\title{
Fe-mordenite/cordierite monolith for the catalytic decomposition of nitrous oxide
}

\author{
Tieqiao Zhou ${ }^{\mathrm{a}, \mathrm{b}}$, Landong $\mathrm{Li}^{\mathrm{b}}$, Cheng Jie ${ }^{\mathrm{b}}$, Qun Shen ${ }^{\mathrm{b}}$, Qiang Xie ${ }^{\mathrm{a}, *}$, Zhengping Hao ${ }^{\mathrm{b}, * *}$ \\ ${ }^{a}$ China University of Mining \& Technology (Beijing), Beijing 100083, PR China \\ ${ }^{\mathrm{b}}$ Research Center for Eco-Environmental Sciences, Chinese Academy of Sciences, Beijing 100085, PR China
}

Received 8 January 2009; received in revised form 3 March 2009; accepted 21 April 2009

Available online 21 May 2009

\begin{abstract}
Mordenite zeolites were coated on cordierite support by in situ hydrothermal method or dip-coating method. The mordenite/cordierite was characterized by X-ray diffraction (XRD) and scanning electron microscope (SEM) techniques and their stability was studied. The mordenite/ cordierite monolith prepared by in situ synthesis showed much better stability than that prepared by dip-coating. Iron was introduced into mordenite/cordierite by ion exchange and Fe-mordenite/cordierite catalyst was prepared. Fe-mordenite/cordierite prepared from in situ synthesis exhibited good activity and stability for $\mathrm{N}_{2} \mathrm{O}$ catalytic decomposition, with great potential for future application.
\end{abstract}

(C) 2009 Elsevier Ltd and Techna Group S.r.l. All rights reserved.

Keywords: D. Cordierite; In situ synthesis; Dip-coating; Mordenite

\section{Introduction}

$\mathrm{N}_{2} \mathrm{O}$ has been recognized as strong greenhouse gas with very long atmospheric lifetime up to $\sim 120$ years, and its global warming potential of $\mathrm{N}_{2} \mathrm{O}$ is about 310 times that of $\mathrm{CO}_{2}$ [1]. Moreover, $\mathrm{N}_{2} \mathrm{O}$ constitutes as the main stratospheric source of pollutant NO and severely destructs the ozone layer [2]. Many efforts have been made to develop end-of-pipe technologies to mitigate $\mathrm{N}_{2} \mathrm{O}$ emission from anthropogenic sources, such as adipic acid production and nitric acid manufacture. An effective way to minimize the impact of $\mathrm{N}_{2} \mathrm{O}$ on the environment is to catalytically decompose $\mathrm{N}_{2} \mathrm{O}$ to environment-friendly $\mathrm{N}_{2}$ and $\mathrm{O}_{2}$ [3-7].

Currently, iron-containing zeolites (such as Fe-ZSM-5) have attracted much attention due to their good catalytic performance under simulated industrial conditions. For practical application, catalysts have to be fixed on structured substrate to form monoliths, thus methods for monolith preparation are very important [8]. Ceramic, especially honeycomb cordierite $\left(2 \mathrm{MgO}-2 \mathrm{Al}_{2} \mathrm{O}_{3}-5 \mathrm{SiO}_{2}\right)$, is the substrate in common use because of its superior mechanical stability and hydrothermal stability as

\footnotetext{
* Corresponding author. Tel.: +861013520151236.

** Corresponding author. Tel.: +861013701018464.

E-mail addresses: dr-xieq@163.com (Q. Xie), zpinghao@rcees.ac.cn (Z. Hao).
}

well as its plasticity. Various coating techniques, e.g. dip-coating and slurry-coating [9], have been developed to deposit catalysts on structured ceramic surfaces. Moreover, for zeolite catalyst, it has been proposed to grow the zeolite directly on ceramic surfaces, so-called in situ hydrothermal synthesis. Up to now, in situ hydrothermal synthesis is proven as suitable technique for making zeolite/ceramic monolith [10,11] and zeolite monolithic catalysts have been employed in several important gas phase reactions, such as the selective catalytic reduction of NOx [12].

In this work, mordenite/cordierite monolith is prepared by in situ hydrothermal synthesis method and by common dipcoating method, respectively. Then active phase of iron is introduced into mordenite/cordierite by ion exchange and $\mathrm{Fe}$-mordenite/cordierite is studied as monolithic catalyst for the decomposition of $\mathrm{N}_{2} \mathrm{O}$. The research aim of this work is to give some hints on the preparation of monolithic Fe-mordenite/ cordierite, with potential application for $\mathrm{N}_{2} \mathrm{O}$ decomposition.

\section{Experimental}

\subsection{Sample preparation}

\subsubsection{Synthesis of mordenite}

For the synthesis of mordenite, tetraethylorthosilicate (TEOS, AR) was used as silicon source and aluminum sulfate 
(AR) as aluminum source. No template was added throughout the synthesis processes. TEOS, sodium hydroxide, aluminum sulfate and water were mixed at the molar ratio of $30 \mathrm{SiO}_{2}: 1 \mathrm{Al}_{2} \mathrm{O}_{3}: 5 \mathrm{Na}_{2} \mathrm{O}: 750 \mathrm{H}_{2} \mathrm{O}$. After 3-h vigorous stirring, the gained transparent liquids were put into a Teflon-lined stainless steel autoclave for static crystallization at $180{ }^{\circ} \mathrm{C}$ for $12 \mathrm{~h}$. Then the samples were taken out, washed with deionized water in ultrasonic waves to remove the unstable adherends on the cordierite, and then dried at $100{ }^{\circ} \mathrm{C}$ overnight.

\subsubsection{In situ synthesis of mordenite/cordierite}

Cordierites (Corning Incorporated, 60 cells $/ \mathrm{cm}^{2}$ ) were pretreated by ultrasonic with diluted $\mathrm{HCl}$ solution. For mordenite to grow on cordierite substrate, the transparent liquid (the same as that for the synthesis of mordenite) and bulk cordierites were put into a Teflon-lined stainless steel autoclave together for static crystallization at $180{ }^{\circ} \mathrm{C}$ for $12 \mathrm{~h}$. The obtained monolithic sample were taken out, washed with deionized water and then dried at $100{ }^{\circ} \mathrm{C}$ overnight.

\subsubsection{Dip-coating of mordenite onto cordierite}

For the dip-coating process, a suspension of 30\% (wt.) mordenite in deionized water ( $\mathrm{pH}$ 6) was used to impregnate the cordierite substrate. The suspension was carefully crushed before dip-coating. Four successive immersions were performed to achieve the zeolite loading of ca. $20 \%$ (wt.), and after each immersion the obtained monolith was blown by hot air and then dried at $150{ }^{\circ} \mathrm{C}$.

\subsubsection{Ion exchange process}

Iron-containing zeolite catalysts were prepared from mordenite/cordierite monolith or mordenite powder by wet ion exchange using ferrous salt at room temperature. For example, $5.0 \mathrm{~g}$ of parent sample was exchanged with $500 \mathrm{~mL}$ $0.05 \mathrm{~mol} / \mathrm{L} \mathrm{FeSO}_{4}$ ( $\mathrm{pH} \sim 3.0$ ) for $48 \mathrm{~h}$ under vigorous stirring in the flowing $\mathrm{N}_{2}$ stream. The as-exchanged samples were then filtered, thoroughly washed, dried at $100{ }^{\circ} \mathrm{C}$ and calcined at $600{ }^{\circ} \mathrm{C}$ for $4 \mathrm{~h}$ in air.

\subsection{Characterization techniques}

The XRD patterns of all samples were measured on a Rigaku powder diffractometer (D/MAX-RB) using $\mathrm{Cu} \mathrm{K} \alpha$ radiation $(\lambda=0.1542 \mathrm{~nm})$ at a scanning rate of $4 \% \mathrm{~min}$ in $2 \theta=5-40^{\circ}$.

SEM images were acquired on a HITACHI S-3500N scanning electron microscope. The samples were covered with a thin layer of gold deposited by sputtering before observation.

The temperature-programmed reduction experiments of samples were carried out on a chemisorption analyzer (Chemisorb 2720, Micromeritics) with 5 vol.\% $\mathrm{H}_{2} / \mathrm{Ar}$ at a heating rate of $10{ }^{\circ} \mathrm{C} / \mathrm{min}$ from 40 to $800{ }^{\circ} \mathrm{C}$. Prior to reduction, the sample was treated in $\mathrm{He}$ at $450{ }^{\circ} \mathrm{C}$ for $1 \mathrm{~h}$.

\subsection{Stability of mordenite/cordierite monolith}

The stability test of mordenite/cordierite monolith samples were carried out on a KQ-800KDE-mode ultrasonic apparatus.
The samples were put into deionized water and treated by ultrasonic for a certain period of time at the power rating of $0.8 \mathrm{~kW}$.

\subsection{Catalytic performance test}

$\mathrm{N}_{2} \mathrm{O}$ decomposition experiments were performed in a fixedbed microreactor at atmospheric pressure. Typically, $0.1 \mathrm{~g}$ powder sample or $0.5 \mathrm{~g}$ monolith sample was placed in a quartz reactor and pretreated in $\mathrm{He}$ at $600{ }^{\circ} \mathrm{C}$ for $1 \mathrm{~h}$. After cooling to $300{ }^{\circ} \mathrm{C}$, the reactant gas mixture $\left(\mathrm{N}_{2} \mathrm{O}\right.$, or $\mathrm{O}_{2}$ or $\mathrm{H}_{2} \mathrm{O}, \mathrm{He}$ balance) was fed into the reactor. The total flow rate of gas mixture was kept at $60 \mathrm{~mL} \mathrm{~min}^{-1}$, i.e. GHSV $=30,000 \mathrm{~h}^{-1}$ (referred to Fe-mordenite). The steady-state tests were conducted isothermally every $25^{\circ} \mathrm{C}$ from 300 to $600{ }^{\circ} \mathrm{C}$ or at a constant reaction temperature of $600{ }^{\circ} \mathrm{C}$. The gas products (after 1-h reaction) were analyzed on-line using a gas chromatograph (Agilent 6820 series) equipped with a TCD detector and two serial columns (a Porapak Q column served for the separation of $\mathrm{N}_{2} \mathrm{O}$ and $\mathrm{N}_{2} / \mathrm{O}_{2}$, and a molecular sieve $5 \AA$ column for the separation of $\mathrm{N}_{2}$ and $\mathrm{O}_{2}$ ).

\section{Results and discussions}

\subsection{Characterization of mordenite/cordierite monolith}

Fig. 1 shows the XRD patterns of blank cordierite, mordenite powder and mordenite/cordierite monolith. As seen in the figure, typical diffraction peaks at $10.4^{\circ}, 18.03^{\circ}, 19.0^{\circ}, 21.6^{\circ}$, $26.4^{\circ}, 28.4^{\circ}, 29.4^{\circ}$ and $33.9^{\circ}$ are observed in the XRD pattern of blank cordierite, corresponding to the structure of ceramic $\left(2 \mathrm{MgO}-2 \mathrm{Al}_{2} \mathrm{O}_{3}-5 \mathrm{SiO}_{2}\right)$. In the XRD pattern of mordenite powders, diffraction peaks corresponding to the typical structure of mordenite are observed [13]. While in XRD patterns of mordenite/cordierite, diffraction peaks of both blank cordierite and mordenite can be observed, suggesting that

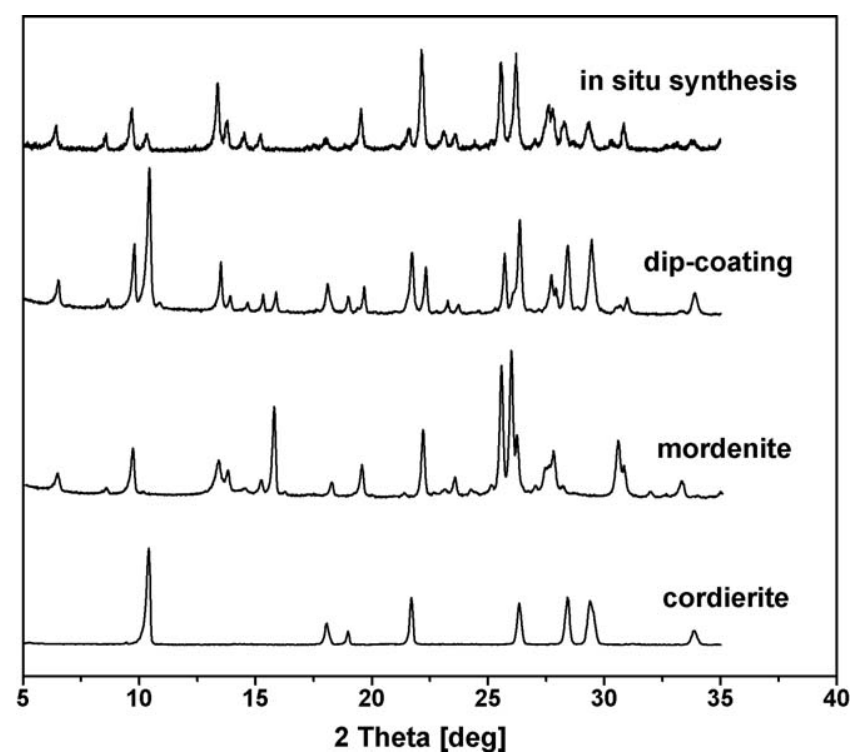

Fig. 1. XRD patterns of blank cordierite, mordenite powder and mordenite/ cordierite monolith prepared by different methods. 
mordenite is successfully coated on the surface of cordierite either by in situ synthesis method or by dip-coating method.

The SEM images of blank cordierite, mordenite and mordenite/cordierite are shown in Fig. 2. The irregular ceramic structure is observed for cordierite support and prisms of about $20 \mu \mathrm{m}$ are observed for mordenite powders. In the images of in situ synthesized mordenite/cordierite, bulk mordenite prisms of about $20 \mu \mathrm{m}$ are observed to coat on external surface of cordierite, while mordenite prisms together with small clubs are observed on the internal surface. It is seen that mordenite tends to form small crystals (i.e. clubs) on the internal surfaces than on the external surfaces. During the process of in situ synthesis, cordierite is the substrate for crystal nucleation and the crystals orientation is thus affected [10]. Besides, the growth of mordenite is also dimensionally restricted by the structure of cordierite when growing on the internal surface. For dip-coated mordenite/cordierite, crushed mordenite prisms are observed to compactly coat on the external surface of cordierite while few mordenite prisms are observed on the internal surface. Obviously, mordenite tends to be coated on the external of cordierite support rather than on internal surface.

\subsection{Stability of mordenite/cordierite monolith}

The stability of mordenite/cordierite monolith is tested by means of ultrasonic treatment and the results are shown in Fig. 3. It is seen that no obvious weight loss can be observed after 1-h treatment for in situ synthesized sample, indicating the good stability of the tested sample. In contrast, nearly $50 \%$ coatings fall off from mordenite/cordierite prepared by dipcoating method after 1 -h treatment. The lack of stability for dipcoated sample may be fatal defect for industrial application.
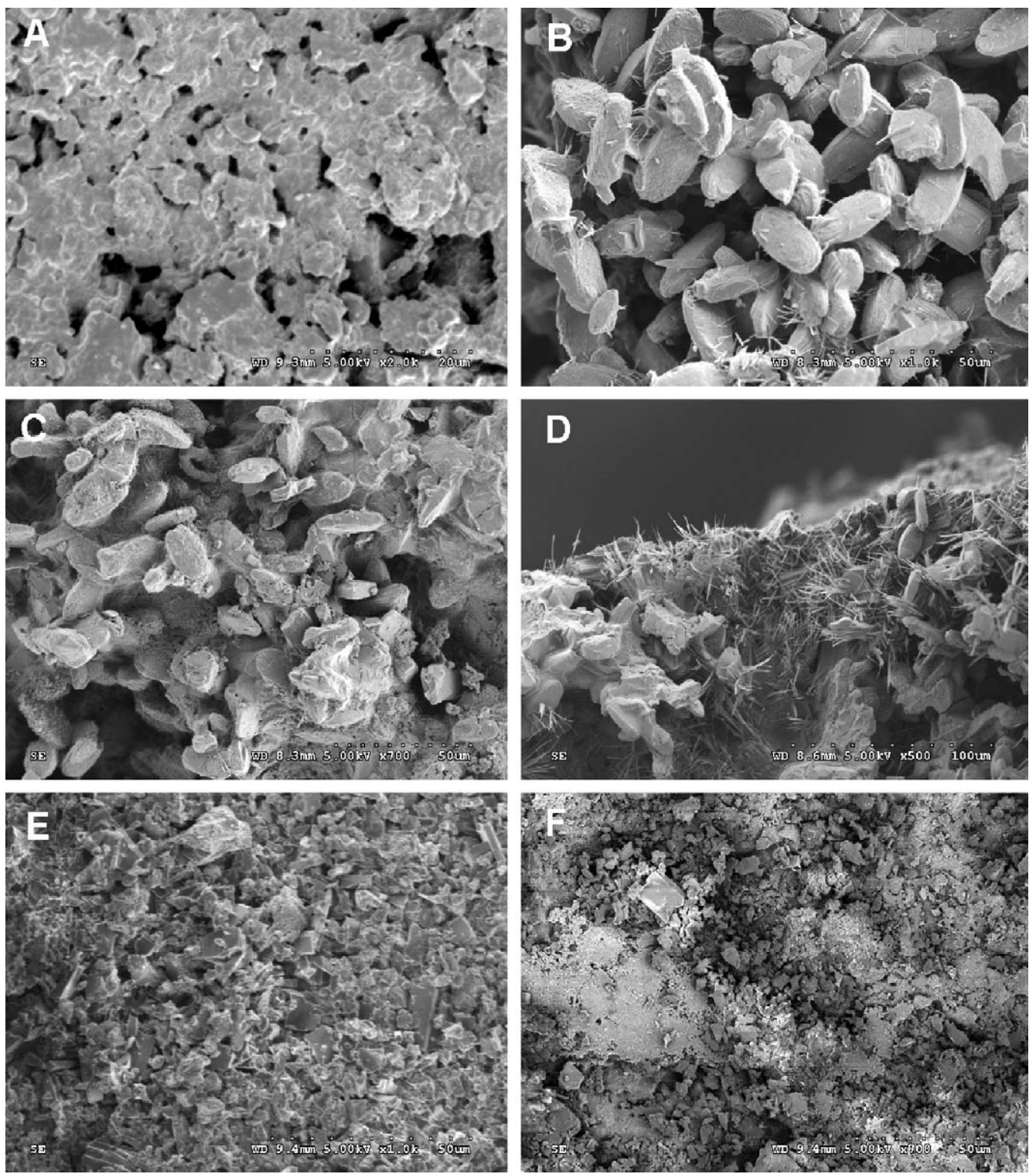

Fig. 2. SEM images of cordierite, mordenite and mordenite/cordierite monolith prepared by different methods: (A) blank cordierite; (B) mordenite powder; (C) external surface of in situ synthesized monolith; (D) internal surface of in situ synthesized monolith; (E) external surface dip-coated monolith; (F) internal surface of dip-coated sample. 


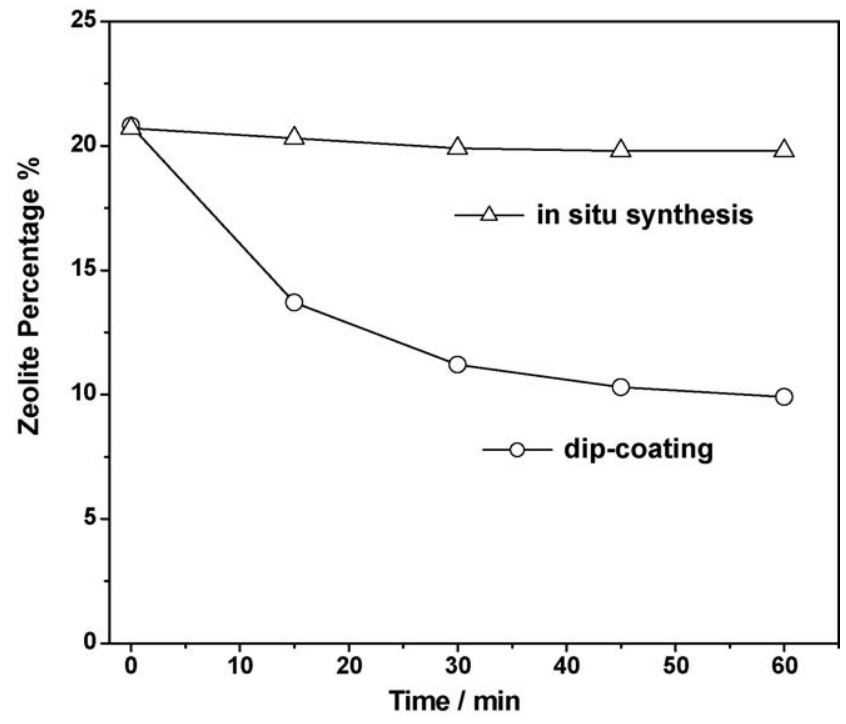

Fig. 3. Stability test of mordenite/cordierite monolith prepared by different methods.

\subsection{Catalytic performance for $\mathrm{N}_{2} \mathrm{O}$ decomposition}

The catalytic activities for $\mathrm{N}_{2} \mathrm{O}$ decomposition over Femordenite powders and $\mathrm{Fe}$-mordenite/cordierite monolith prepared by different methods are shown in Fig. 4. As for Fe-mordenite, $\mathrm{N}_{2} \mathrm{O}$ decomposition starts at about $450{ }^{\circ} \mathrm{C}$ and the $50 \% \mathrm{~N}_{2} \mathrm{O}$ conversion occur at $560{ }^{\circ} \mathrm{C}$. The dip-coated $\mathrm{Fe}$ mordenite/cordierite exhibits nearly identical activity for $\mathrm{N}_{2} \mathrm{O}$ decomposition to $\mathrm{Fe}$-mordenite powder with similar mordenite loadings. Based on the preparation process, dip-coated $\mathrm{Fe}$ mordenite/cordierite monolith can be even thought as a mechanical mixture of Fe-mordenite powder and cordierite support. While for in situ synthesized Fe-mordenite/cordierite, an improved activity for $\mathrm{N}_{2} \mathrm{O}$ decomposition is observed when

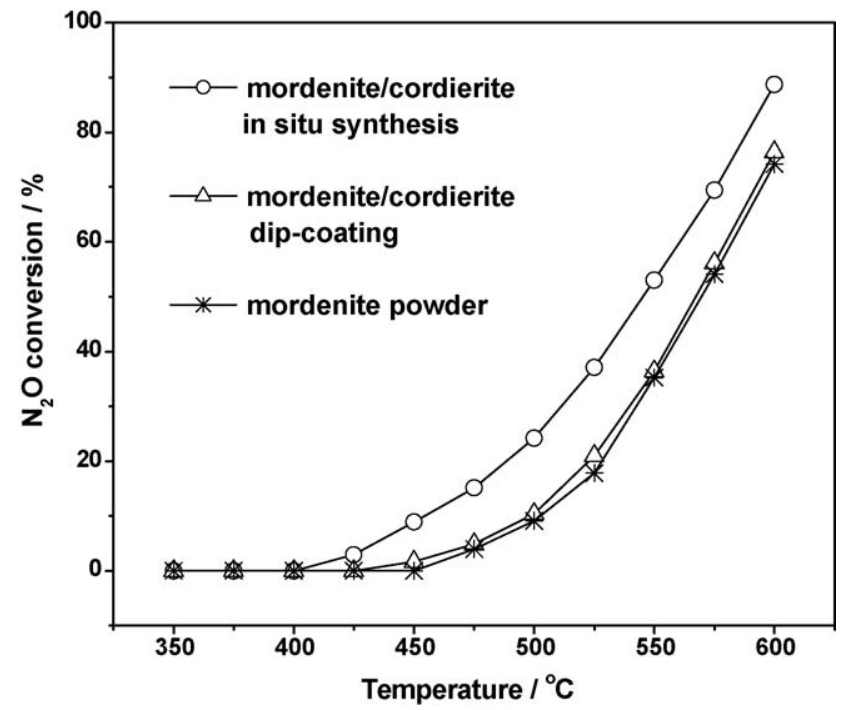

Fig. 4. $\mathrm{N}_{2} \mathrm{O}$ catalytic decomposition on Fe-mordenite powder and Fe-mordenite/cordierite monolith. Reaction conditions: $0.1 \mathrm{~g}$ powder or $0.5 \mathrm{~g}$ monolith, $0.5 \% \mathrm{~N}_{2} \mathrm{O}, 5 \% \mathrm{O}_{2}$, balance $\mathrm{He}, \mathrm{GHSV}=30,000 \mathrm{~h}^{-1}$ (referred to zeolite loadings). compared to Fe-mordenite powder and nearly 90\% $\mathrm{N}_{2} \mathrm{O}$ conversion can be obtained at $600{ }^{\circ} \mathrm{C}$. The improved activity may be attributed to the better accessibility of zeolite coating derived from in situ synthesis method [14]. By in situ synthesis, the zeolite crystals directly nucleate on cordierite support and mainly grow along certain direction. The order in crystal growth and the highly dispersion of zeolite crystals greatly improves the accessibility of zeolites and which effectively avoided the "dead volume" caused by the random packing of zeolites. When iron is introduced to mordenite/cordierite, the agglomeration of iron to bulk iron oxides induced by calcination can be prevented to some extend. Bulk iron oxides are known to play a negative role for $\mathrm{N}_{2} \mathrm{O}$ decomposition [15], and thus in situ synthesized Fe-mordenite/cordierite shows better activity for $\mathrm{N}_{2} \mathrm{O}$ decomposition.

The formation of iron oxides in Fe-mordenite and $\mathrm{Fe}$ mordenite/cordierite is analyzed by means of $\mathrm{H}_{2}$-TPR. As seen in Fig. 5, the reduction of $\mathrm{Fe}$ species starts at $200^{\circ} \mathrm{C}$ and continues to over $750{ }^{\circ} \mathrm{C}$. Based on previous investigations, the reduction peaks in the range of $250-450{ }^{\circ} \mathrm{C}$ are attributed to the reduction of ion-exchanged $\mathrm{Fe}$ species in tetrahedral or octahedral coordination, while the reduction peaks at 550$750{ }^{\circ} \mathrm{C}$ are attributed to the reduction of bulk iron oxides $[16,17]$. It is seen that a large proportion of bulk iron oxides exist in Fe-mordenite and dip-coated Fe-mordenite/cordierite while the iron oxides in in situ synthesized Fe-mordenite/ cordierite can nearly be ignored. The formation of bulk iron oxides is greatly suppressed in Fe-mordenite/cordierite due to the orientation of crystal growth during in situ synthesis [18] and the catalytic activity for $\mathrm{N}_{2} \mathrm{O}$ decomposition is greatly improved in such a way.

The durability of $\mathrm{Fe}$-mordenite/cordierite catalyst prepared by in situ method in the absence or presence of $\mathrm{H}_{2} \mathrm{O}$ was further investigated. Time-on-stream profiles in Fig. 6 show that the $\mathrm{N}_{2} \mathrm{O}$ conversion is about $88 \%$ at $600{ }^{\circ} \mathrm{C}$ and remained almost unchanged for $60 \mathrm{~h}$, indicating that the catalyst is highly durable under these conditions. The presence of $2.5 \% \mathrm{H}_{2} \mathrm{O}$

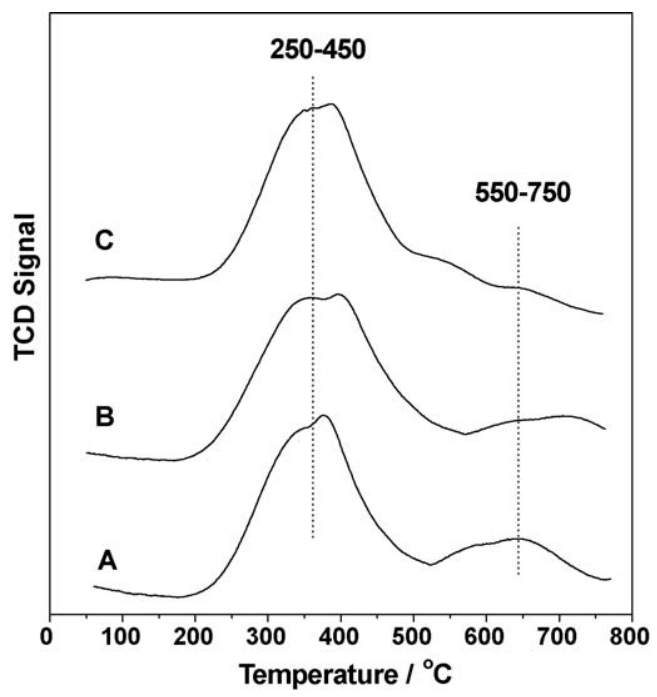

Fig. 5. $\mathrm{H}_{2}$-TPR profiles of Fe-mordenite powder (A), Fe-mordenite/cordierite monolith prepare by dip-coating method (B) and in situ synthesis (C). 


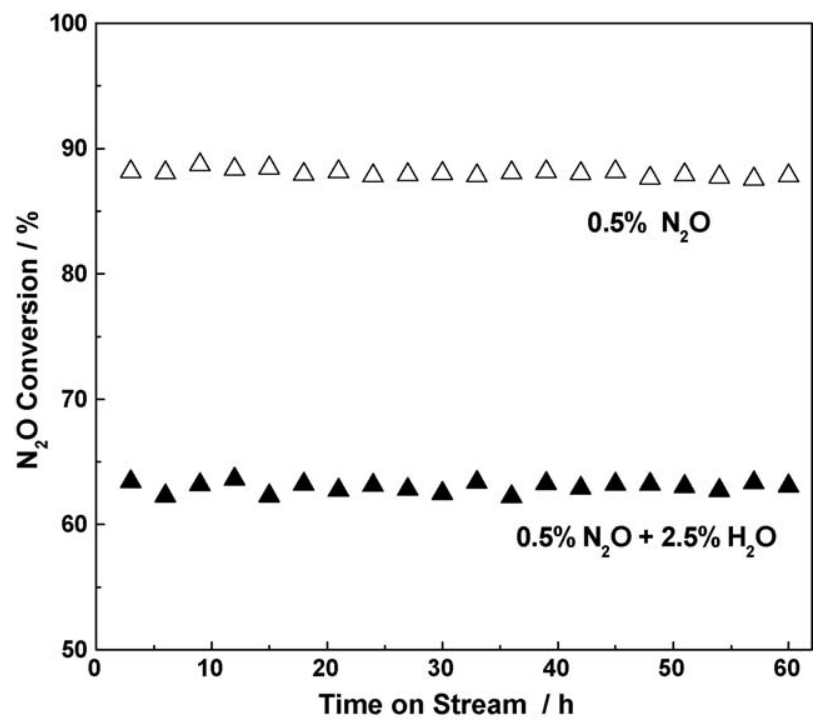

Fig. 6. Time-on-stream behavior of Fe-mordenite/cordierite for $\mathrm{N}_{2} \mathrm{O}$ decomposition at $600{ }^{\circ} \mathrm{C}$. Reaction conditions: $0.5 \mathrm{~g}$ catalyst, $0.5 \% \mathrm{~N}_{2} \mathrm{O}, 5 \% \mathrm{O}_{2}, 0$ or $2.5 \% \mathrm{H}_{2} \mathrm{O}$, balance $\mathrm{He}$, GHSV $=30,000 \mathrm{~h}^{-1}$.

shows obvious negative effect on $\mathrm{N}_{2} \mathrm{O}$ decomposition and the $\mathrm{N}_{2} \mathrm{O}$ conversion decreases from about $88 \%$ to about $63 \%$. Good durability of $\mathrm{Fe}$-mordenite/cordierite is also achieved in the presence of $\mathrm{H}_{2} \mathrm{O}$, which demonstrates its potential for future application.

\section{Conclusion}

Mordenite/cordierite monolith is prepared by in situ hydrothermal synthesis method or by common dip-coating method. The as-prepared monoliths are characterized by means of XRD and SEM techniques. The monolithic sample prepared by in situ method exhibits much better stability than the sample prepared by dip-coating. Fe-mordenite/cordierite monolith exhibits good activity and stability for $\mathrm{N}_{2} \mathrm{O}$ decomposition, which demonstrates its potential for application.

\section{Acknowledgements}

This work was financially supported by National High Technology Research and Development Program of China (no. 2006AA06A310) and the National Natural Science Foundation of China (no. 20877088).

\section{References}

[1] J. Pérez-Ramírez, Prospects of $\mathrm{N}_{2} \mathrm{O}$ emission regulations in the European fertilizer industry, Appl. Catal. B 70 (2007) 31-35.

[2] M.J. Prather, Time scales in atmospheric chemistry: coupled perturbations to $\mathrm{N}_{2} \mathrm{O}, \mathrm{NO}_{y}$, and $\mathrm{O}_{3}$, Science 279 (1998) 1339-1341.

[3] J. Pérez-Ramírez, F. Kapteijin, G. Mul, J.A. Moulijn, NO-assisted $\mathrm{N}_{2} \mathrm{O}$ decomposition over Fe-based catalysts: effects of gas-phase composition and catalyst constitution, J. Catal. 208 (2002) 211-223.

[4] G.D. Pirngruber, M. Luechinger, P.K. Roy, A. Cecchetto, P. Smirniotis, $\mathrm{N}_{2} \mathrm{O}$ decomposition over iron-containing zeolites prepared by different methods: a comparison of the reaction mechanism, J. Catal. 224 (2004) 429-440.

[5] I. Melián-Cabrera, C. Mentruit, J.A.Z. Pieterse, R.W. van den Brink, G. Mul, F. Kapteijn, J.A. Moulijn, Highly active and stable ion-exchanged $\mathrm{Fe}$-ferrierite catalyst for $\mathrm{N}_{2} \mathrm{O}$ decomposition under nitric acid tail gas conditions, Catal. Commun. 6 (2005) 301-305.

[6] L.D. Li, Q. Shen, J.J. Yu, Z.P. Hao, Z.P. Xu, G.Q. Max Lu, Fe-USY zeolite catalyst for effective decomposition of nitrous oxide, Environ. Sci. Technol. 41 (2007) 7901-7906.

[7] M.A.G. Hevia, J. Pérez-Ramírez, Assessment of the low-temperature EnviNOx variant for catalytic $\mathrm{N}_{2} \mathrm{O}$ abatement over steam-activated FeZSM-5, Appl. Catal. B 77 (2008) 248-254.

[8] R.M. Heck, S. Gulati, R.J. Farrauto, The application of monoliths for gas phase catalytic reactions, Chem. Engl. J. 82 (2001) 149-156.

[9] P. Avila, M. Montes, E.E. Miró, Monolithic reactors for environmental applications-a review on preparation technologies, Chem. Engl. J. 109 (2005) 11-36.

[10] L.D. Li, B. Xue, J.X. Chen, N.J. Guan, F.X. Zhang, H.Q. Feng, D.X. Liu, Direct synthesis of zeolite coatings on cordierite supports by in situ hydrothermal method, Appl. Catal. A 292 (2005) 312-321.

[11] V. Meille, Review on methods to deposit catalysts on structured surfaces, Appl. Catal. A 315 (2006) 1-17.

[12] L.D. Li, J.X. Chen, S.J. Zhang, N.J. Guan, T.Y. Wang, S.L. Liu, Selective catalytic reduction of nitrogen oxides from exhaust of lean burn engine over in-situ synthesized Cu-ZSM-5/cordierite, Environ. Sci. Technol. 39 (2005) 2841-2847.

[13] Ch. Baerlocher, W.M. Meier, D.H. Olson, Atlas of Zeolitic Framework Types, Elsevier, 2001.

[14] M.A. Ulla, E. Miro, R. Mallada, J. Coronas, J. Santamaría, Preparation of highly accessible mordenite coatings on ceramic monoliths at loading exceeding $50 \%$ by weight, Chem. Commun. 5 (2004) 528-529.

[15] L.D. Li, Q. Shen, J.J. Li, Z.P. Hao, Z.P. Xu, G.Q. Max Lu, Iron-exchanged FAU zeolites: preparation, characterization and catalytic properties for $\mathrm{N}_{2} \mathrm{O}$ decomposition, Appl. Catal. A 344 (2008) 131-141.

[16] El-M. El-Malki, R.A. van Santen, W.M.H. Sachtler, Introduction of Zn, $\mathrm{Ga}$, and Fe into HZSM- 5 cavities by sublimation: identification of acid sites, J. Phys. Chem. B 103 (1999) 4611-4622.

[17] H.Y. Chen, W.M.H. Sachtler, Activity and durability of Fe/ZSM-5 catalysts for lean burn NOx reduction in the presence of water vapor, Catal. Today 42 (1998) 73-83.

[18] S. Mintova, J. Hedlund, V. Valtchev, B. Schoeman, J. Sterte, ZSM-5 films prepared from template-free precursors, J. Mater. Chem. 8 (1998) 2217-2221. 